Article

\title{
Coordination of manganese porphyrins on amino-functionalized MCM-41 for heterogeneous catalysis of naphthalene hydroxylation
}

\author{
Fu Yang, Shuying Gao, Cuirong Xiong, Haiqing Wang, Jin Chen, Yan Kong* \\ State Key Laboratory of Materials-Oriented Chemical Engineering, College of Chemistry and Chemical Engineering, Nanjing Technology University, \\ Nanjing 210009, Jiangsu, China
}

\section{A R T I C L E I N F O}

\section{Article history:}

Received 9 January 2015

Accepted 17 March 2015

Published 20 July 2015

\section{Keywords:}

Manganese porphyrin

Immobilization

Axial coordination

Naphthalene hydroxylation

Heterogeneous catalysis

\begin{abstract}
A B S T R A C T
The different amounts of [5,10,15,20-tetrakis-(pentafluorophenyl)porphyrin] manganese chloride $\left(\mathrm{TF}_{20} \mathrm{PPMnCl}\right)$ were immobilized on amino-functionalized MCM- 41 for catalysis of the hydroxylation of naphthalene. The samples were characterized by X-ray powder diffraction, $\mathrm{N}_{2}$ adsorption/desorption isotherms, Fourier transform infrared spectroscopy, X-ray photoelectron spectroscopy, scanning electron microscopy, diffuse reflectance ultraviolet-visible spectroscopy, thermogravimetric and differential scanning calorimetry, and inductively coupled plasma mass spectrometry. The results indicated that the manganese porphyrins were axially coordinated on amino-functionalized MCM-41. The prepared samples showed remarkable catalytic activity in the hydroxylation of naphthalene with meta-chloroperbenzoic acid as the oxidant. The catalyst could be reused several times without loss of its activity.
\end{abstract}

(C) 2015, Dalian Institute of Chemical Physics, Chinese Academy of Sciences. Published by Elsevier B.V. All rights reserved.

\section{Introduction}

The products of selective oxidation of aromatic compounds are often used as raw materials and intermediates in chemical industries [1-6]. For example, naphthol from the oxidation of naphthalene is widely used in medicines, dyes, perfumes, and antioxidants. Currently, naphthol is mainly produced by sulfonation/alkali-fusion from isopropyl naphthalene. However, these methods are time consuming and can produce toxic byproducts that cause environmental pollution. Thus, direct hydroxylation of naphthalene to naphthol has attracted considerable attention [7]. In particular, research has focused on the use of efficient catalysts for this reaction.

Many studies have looked at homogeneous catalysts, such as metalloporphyrins, because of their excellent catalytic activity in the direct hydroxylation of naphthalene [8-11]. However, homogeneous catalysts are difficult to recycle, which may hinder their practical application. Heterogeneous catalysts, such as mesoporous silica loaded with transition metals, have been investigated for direct catalysis of the hydroxylation of naphthalene, but the final yields are low $[12,13]$.

Therefore, a heterogeneous catalyst with both high catalytic performance and good reusability needs to be developed. Mesoporous silica, such as MCM-41, is an ideal matrix for the base support material of such a catalyst because it has high specific surface area, appropriate pore size, and large pore volume and its surface is easy to modify.

The aim of this study was to produce a heterogeneous catalyst by immobilizing [5,10,15,20-tetrakis-(pentafluorophenyl) porphyrin] manganese chloride $\left(\mathrm{TF}_{20} \mathrm{PPMnCl}\right)$ on amino-functionalized MCM-41. Various characterization techniques were chosen to confirm anchorage of $\mathrm{TF}_{20} \mathrm{PPMnCl}$ on the $\mathrm{MCM}-41$

\footnotetext{
* Corresponding author. Tel/Fax: +86-25-83587860; E-mail: kongy36@njtech.edu.cn This work was supported by the National Natural Science Foundation of China $(21276125,21476108)$. DOI: 10.1016/S1872-2067(15)60836-1 | http://www.sciencedirect.com/science/journal/18722067 | Chin. J. Catal., Vol. 36, No. 7, July 2015
} 
support. In addition, the catalytic activity and reusability of materials in direct hydroxylation of naphthalene with meta-chloroperoxybenzoic acid ( $m$-CPBA) as an oxidant were studied.

\section{Experimental}

\subsection{Materials}

Cetyltrimethylammonium bromide, manganese chloride tetrahydrate $\left(\mathrm{MnCl}_{2} \cdot 4 \mathrm{H}_{2} \mathrm{O}\right)$, sodium silicate nonahydrate, ethanol, acetonitrile, toluene, propionic acid, dimethylformamide (DMF), naphthalene, dichloromethane and pyrrole were purchased from Sinopharm Chemical Reagent Co. Ltd (Shanghai, China). Perfluorobenzaldehyde and 3-aminopropyltriethoxysilane (APTES) were purchased from Tokyo TCI (Shanghai) Development Co. Ltd (Shanghai, China). All reagents were of analytical grade. $m$-CPBA (purity 75\%) was purchased from Aladdin (Shanghai, China).

\subsection{Preparation of the catalysts}

\subsubsection{Synthesis of MCM-41}

Pure MCM-41 was prepared as reported previously [14]. Typically, $3.64 \mathrm{~g}$ of cetyltrimethylammonium bromide and $11.36 \mathrm{~g}$ of $\mathrm{Na}_{2} \mathrm{SiO}_{3} \cdot 9 \mathrm{H}_{2} \mathrm{O}$ were dissolved in $100 \mathrm{~mL}$ of distilled water at $80^{\circ} \mathrm{C}$. After cooling to room temperature, the solution was adjusted to $\mathrm{pH}=9.5 \mathrm{using}$ sulfuric acid ( $1 \mathrm{~mol} / \mathrm{L})$. The obtained gel was transferred to a Teflon stainless autoclave and aged at $100{ }^{\circ} \mathrm{C}$ for $3 \mathrm{~d}$. The product was centrifuged and washed with distilled water three times and then with ethanol three times. The sample was calcined at $550{ }^{\circ} \mathrm{C}$ for $5 \mathrm{~h}$ in a stream of dry air to obtain MCM-41.

\subsubsection{Amino-functionalization of MCM-41}

According to the literature [15], $40 \mathrm{~mL}$ of toluene, $0.3 \mathrm{~g}$ of MCM-41, and $0.1 \mathrm{~mL}$ of APTES were added to a three-neck round-bottom flask equipped with a magnetic stirrer and a reflux condenser. After stirring in a $70^{\circ} \mathrm{C}$ water bath for $12 \mathrm{~h}$, the product was filtered, washed and dried at $60{ }^{\circ} \mathrm{C}$. The product was labeled as N-MCM-41.

\subsubsection{Synthesis of porphyrins and metalloporphyrins}

The free base porphyrin [5,10,15,20-tetrakis(pentafluorophenyl)porphyrin] $\left(\mathrm{H}_{2} \mathrm{TF}_{20} \mathrm{PP}\right)$ was prepared according to an established procedure [16]. For the metallation of $\mathrm{H}_{2} \mathrm{TF}_{20} \mathrm{PP}$ [17], in a three-neck flask, $200 \mathrm{mg}$ of $\mathrm{H}_{2} \mathrm{TF}_{20} \mathrm{PP}$ and $1 \mathrm{~g}$ of $\mathrm{CH}_{3} \mathrm{COONa}$ were dissolved in $100 \mathrm{~mL}$ of DMF. Manganese chloride tetrahydrate $(20 \mathrm{mmol})$ was added, and the mixture was refluxed at $80{ }^{\circ} \mathrm{C}$ under a nitrogen atmosphere for $2 \mathrm{~h}$. After cooling the resulting solution to room temperature, the product was collected by centrifugation and washed with DMF and water, and the product was labeled as $\mathrm{TF}_{20} \mathrm{PPMnCl}$.

\subsubsection{Synthesis of $M n\left(T F_{5} P P\right)-M C M-41$}

Different amounts of $\mathrm{TF}_{20} \mathrm{PPMnCl}$ were immobilized on the MCM-41 support by controlling the $\mathrm{TF}_{20} \mathrm{PPMnCl} / \mathrm{N}-\mathrm{MCM}-41$ mass ratio at $0.2,0.3,0.4$, and 0.5 . The synthesis of $\mathrm{Mn}\left(\mathrm{TF}_{5} \mathrm{PP}\right)-\mathrm{MCM}-41$ was carried out as described previously [18]. Briefly, $0.1 \mathrm{~g}$ of N-MCM-41 was dispersed in $20 \mathrm{~mL}$ of a mixed solution of dichloromethane and ethanol $(1: 2, V / V)$ containing a set amount of $\mathrm{TF}_{20} \mathrm{PPMnCl}$. The solution was stirred for $24 \mathrm{~h}$ in $50{ }^{\circ} \mathrm{C}$ water bath equipped with magnetic stirrer and a reflux condenser. Finally, the product was isolated by filtration and washed with ethanol several times to obtain the catalyst $\mathrm{Mn}\left(\mathrm{TF}_{5} \mathrm{PP}\right)-\mathrm{MCM}-41$. For the $\mathrm{TF}_{20} \mathrm{PPMnCl} / \mathrm{N}-\mathrm{MCM}-41$ mass ratios of $0.2,0.3,0.4$, and 0.5 , the products were labeled as $x$-Mn(TF5 $\mathrm{PP})-\mathrm{MCM}-41$, where $x=2,3,4$, or 5 , respectively.

\subsection{Characterization}

X-ray powder diffraction (XRD) patterns were recorded on a Bruker AXS D8 Advance (Billerica, MA) powder diffractometer with Ni filtered $\mathrm{Cu} K_{\alpha}$ radiation $(\lambda=0.154178 \mathrm{~nm})$.

Nitrogen adsorption/desorption measurements were carried out at $196{ }^{\circ} \mathrm{C}$ on a Micromeritics ASAP-2000 (Norcross, GA). Before the measurements, the calcined samples were outgassed under vacuum at $100{ }^{\circ} \mathrm{C}$ for $4 \mathrm{~h}$. The specific surface area and the pore size distribution were calculated by the Brunauer-Emmet-Teller (BET) and Barrett-Joyner-Halenda methods, respectively.

Fourier transform infrared (FT-IR) spectra of the samples were obtained in the range $400-4000 \mathrm{~cm}^{-1}$ with powders dispersed in $\mathrm{KBr}$ using a Bruker VECTOR 22 spectrometer.

$\mathrm{X}$-ray photoelectron spectroscopy (XPS) was conducted on a PHI 5000 Versa Probe spectrometer (Physical Electronics, Chanhassen, $\mathrm{MN}$ ) with $\mathrm{Al} K_{\alpha}$ radiation (1486.6 eV). The C $1 s$ peak at $284.6 \mathrm{eV}$ was used as the reference for binding energy.

Field emission scanning electron microscopy images of the samples were recorded using a Hitachi S4800 (Tokyo, Japan).

Diffuse reflectance ultraviolet-visible (UV-Vis) spectra of the samples were obtained in the range of 200-800 $\mathrm{nm}$ by a Perkin-Elmer Lambda 35 spectrometer.

Thermogravimetric and differential scanning calorimetry (TG-DSC) patterns were obtained using a Hitachi TGA integrated thermal differential thermal analyzer (simultaneous thermal analyzer, EXSTAR TG/DTA7000).

Manganese contents in the catalysts were measured using a Jarrell-Ash 1100 inductively coupling plasma mass spectrometer.

\subsection{Catalysis tests}

Hydroxylation of naphthalene was carried out with $1 \mathrm{~g}$ of naphthalene, $20 \mathrm{~mL}$ of dichloromethane, $20 \mathrm{~mL}$ of acetonitrile, $0.1 \mathrm{~g}$ of catalyst, and $1.35 \mathrm{~g}$ of $\mathrm{m}$-CPBA. After $4 \mathrm{~h}$ at $30^{\circ} \mathrm{C}$, the products were analyzed by an SP-6890 gas chromatograph (Lunan Ruihong Chemical Instrument Co. Ltd, Lunan, China) with an SE-54 capillary column $(0.32 \mathrm{~mm} \times 30 \mathrm{~m})$. The conversion and selectivity were calculated by the internal standard method with 1,2-dimethoxybenzene.

To investigate reuse of the $\mathrm{Mn}\left(\mathrm{TF}_{5} \mathrm{PP}\right)-\mathrm{MCM}-41$, the solid catalyst was separated from the reaction mixture by centrifugation and used again in a new reaction. 


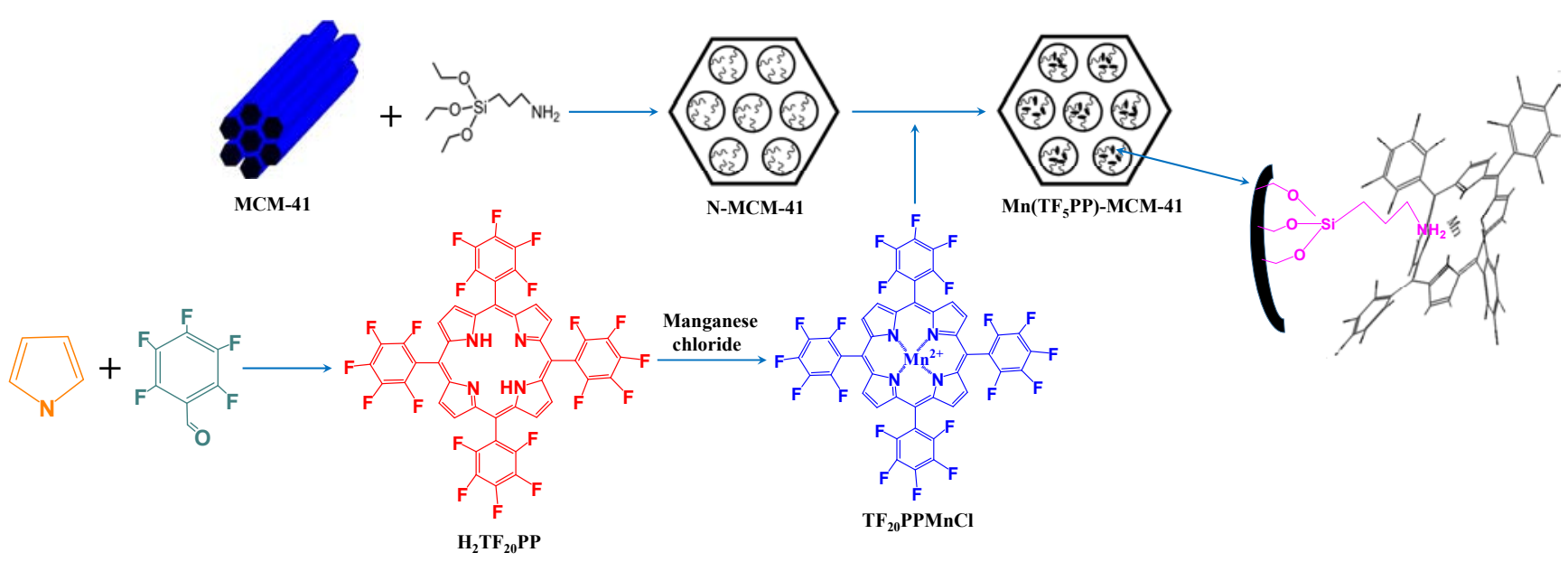

Scheme 1. Synthesis of the $\mathrm{Mn}\left(\mathrm{TF}_{5} \mathrm{PP}\right)-\mathrm{MCM}-41$ catalyst.

\section{Results and discussion}

Scheme 1 shows the procedure for immobilizing $\mathrm{TF}_{20} \mathrm{PPMnCl}$ on APTES modified MCM-41. First, N-MCM-41 was prepared by reaction of APTES with MCM-41. In the next step, $\mathrm{TF}_{20} \mathrm{PPMnCl}$ was reacted with N-MCM-41, and this resulted in axial coordination to provide the catalyst.

\subsection{XRD results}

Fig. 1 shows the small-angle XRD patterns of some samples. The (100) diffraction peak at $2 \theta=2^{\circ}-3^{\circ}$ indicated that all the samples exhibited the characteristics of a typical mesoporous structure. As for pure MCM-41, three weak peaks ascribed to (110), (200), and (210) reflections confirmed a highly-ordered two-dimensional hexagonal $(p 6 \mathrm{~mm})$ structure [19]. The peaks of N-MCM-41 and 5-Mn(TF5 PP)-MCM-41 were weaker and broader than those of the matrix MCM-41, which demonstrated that the long-range order in the mesoporous material decreased with addition of APTES and $\mathrm{TF}_{20} \mathrm{PPMnCl}$. Meanwhile, the (100) reflection peak shifted to a higher $2 \theta$ value, revealing a decrease in the $d_{100}$ spacing, which may be caused by the or-

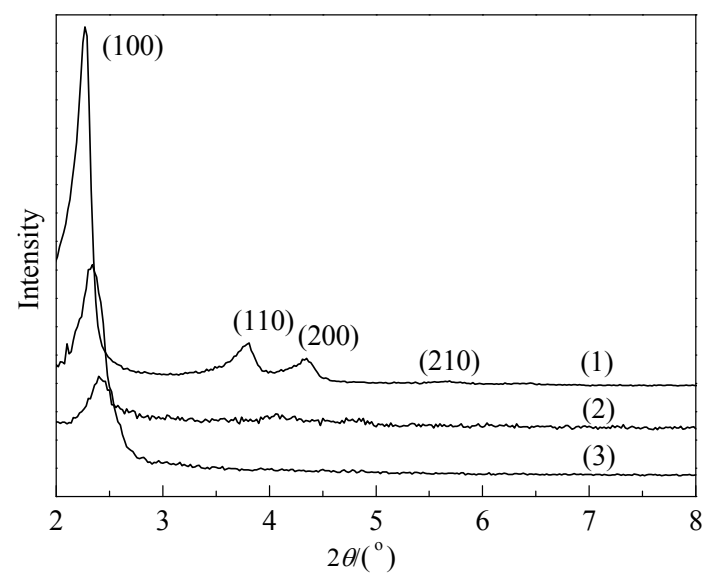

Fig. 1. XRD patterns of MCM-41 (1), N-MCM-41 (2) and 5-Mn(TF 5 PP)-MCM-41 (3). ganic compounds on the surface of MCM-41. Although the (110), (200), and (210) peaks were unable to be identified because of their low intensity, the existence of (100) diffraction peaks of N-MCM-41 and 5-Mn(TF5 PP)-MCM-41 revealed that the mesophase of the host materials was still maintained.

\section{2. $N_{2}$ adsorption/desorption results}

The $\mathrm{N}_{2}$ adsorption/desorption isotherms and pore size distributions of MCM-41, N-MCM-41, and 2-Mn(TF5 PP)-MCM-41 are shown in Fig. 2. Pure MCM-41 exhibited a typical IV isotherm with an H1 hysteresis loop. A steep increase in the absorption volume at relative pressures $\left(p / p_{0}\right)$ ranging from 0.2 to 0.4 indicated that the sample had a highly ordered mesopo-
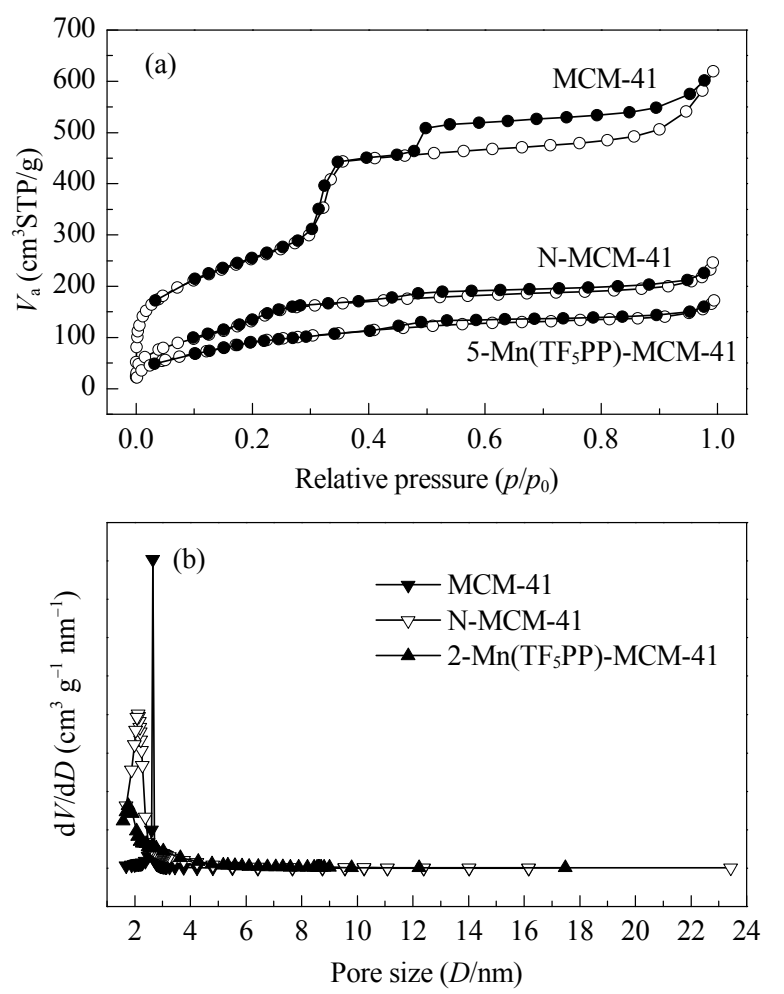

Fig. 2. $\mathrm{N}_{2}$ adsorption/desorption isotherms (a) and pore size distribution (b) of MCM-41, N-MCM-41, and 2-Mn(TF5 PP)-MCM-41. 
Table 1

Structural properties of MCM-41, N-MCM-41 and 2-Mn(TF5 PP)MCM-41.

\begin{tabular}{lccc}
\hline Sample & $\begin{array}{c}A_{\text {BET }} \\
\left(\mathrm{m}^{2} / \mathrm{g}\right)\end{array}$ & $\begin{array}{c}\text { Pore diameter } \\
(\mathrm{nm})\end{array}$ & $\begin{array}{c}\text { Pore volume } \\
\left(\mathrm{cm}^{3} / \mathrm{g}\right)\end{array}$ \\
\hline MCM-41 & 1183 & 2.65 & 0.8562 \\
N-MCM-41 & 527 & 2.12 & 0.3221 \\
2-Mn(TF5)-MCM-41 & 317 & 1.77 & 0.2434 \\
\hline
\end{tabular}

rous structure. The $\mathrm{N}_{2}$ adsorption volumes of $\mathrm{N}-\mathrm{MCM}-41$ and 2-Mn(TF5 PP)-MCM-41 decreased sharply, and the capillary condensation step shifted to a lower relative pressure, which indicated a gradual decrease in the pore size. Some structural parameters of the samples are summarized in Table 1. Compared with MCM-41, the N-MCM-41 and 2-Mn(TF5 $\mathrm{PP})-\mathrm{MCM}-41$ samples exhibited relatively low BET surface areas and pore volumes. Moreover, it should be noted that the pore size showed a significant decrease from $2.65 \mathrm{~nm}$ for MCM-41 to $2.17 \mathrm{~nm}$ for N-MCM-41 and $1.77 \mathrm{~nm}$ for $2-\mathrm{Mn}\left(\mathrm{TF}_{5} \mathrm{PP}\right)-\mathrm{MCM}-41$ (Fig. 2(b)). This decrease in pore size supports the small-angle XRD results (Section 3.1). These observations confirm that APTES and $\mathrm{TF}_{20} \mathrm{PPMnCl}$ were successfully incorporated into the substrate MCM-41.

\subsection{FT-IR results}

The FT-IR spectra of $\mathrm{TF}_{20} \mathrm{PPMnCl}$, MCM-41, N-MCM-41, and $5-\mathrm{Mn}\left(\mathrm{TF}_{5} \mathrm{PP}\right)-\mathrm{MCM}-41$ are shown in Fig. 3. The peaks at around 1090 (shoulder at 1250) and $800 \mathrm{~cm}^{-1}$ could be attributed to asymmetric and symmetric stretching vibrations of $\mathrm{Si}-\mathrm{O}$, respectively. The broad band at approximately $3400 \mathrm{~cm}^{-1}$ could be attributed to the stretching vibration of surface $\mathrm{O}-\mathrm{H}$. For N-MCM-41, the peak around $2923 \mathrm{~cm}^{-1}$ was assigned to the stretching vibration of $\mathrm{CH}_{2}$. The intensity of the peak at 800 $\mathrm{cm}^{-1}$ increased for N-MCM-41 compared to MCM-41, which was attributed to the emergence of an out-plane bending vibration of $\mathrm{N}-\mathrm{H}$ in N-MCM-41 [20]. Based on these findings, we concluded that APTES was successfully grafted on MCM-41.

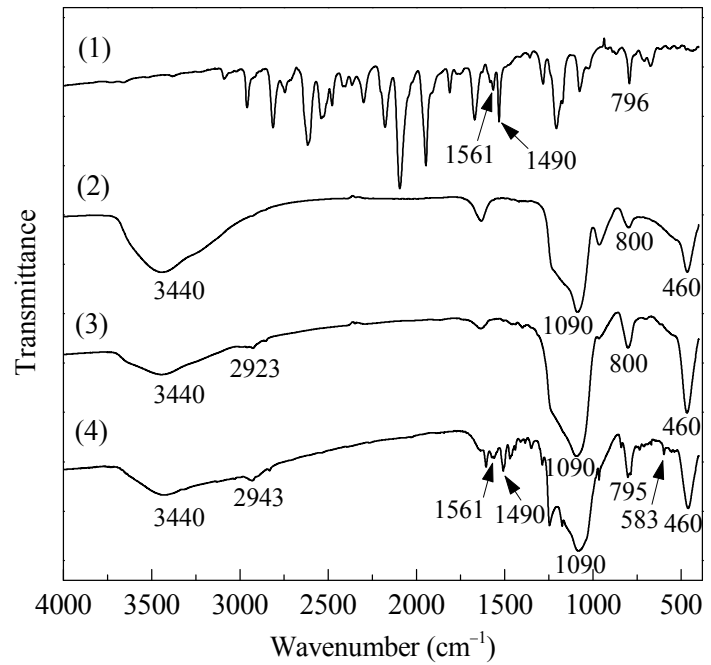

Fig. 3. FT-IR spectra of $\mathrm{TF}_{20} \mathrm{PPMnCl}$ (1), MCM-41 (2), N-MCM-41 (3), and $5-\mathrm{Mn}\left(\mathrm{TF}_{5} \mathrm{PP}\right)-\mathrm{MCM}-41$ (4).

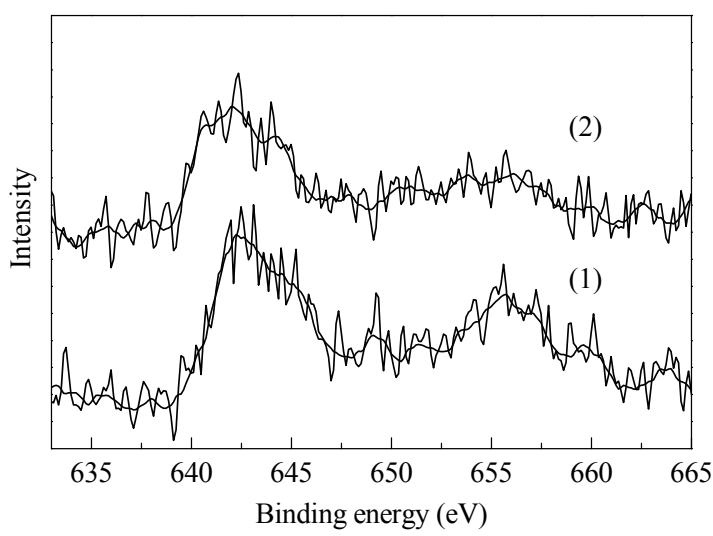

Fig. 4. Mn $2 p$ XPS spectra of $\mathrm{TF}_{20} \mathrm{PPMnCl}(1)$ and $5-\mathrm{Mn}\left(\mathrm{TF}_{5} \mathrm{PP}\right)-\mathrm{MCM}-41$ (2).

In the spectrum of 5-Mn( $\left.\mathrm{TF}_{5} \mathrm{PP}\right)-\mathrm{MCM}-41$, absorption peaks were observed at 1561 and $1490 \mathrm{~cm}^{-1}$. According to Zhu et al. [17], these two peaks are caused by the vibrations of $\mathrm{C}=\mathrm{N}$ and $\mathrm{C}=\mathrm{C}$. Therefore, these results indicated that the porphyrin tetrapyrrole ring is anchored on the surface of the mesoporous silica. The red shift of the out-of-plane bending vibration of $\mathrm{N}-\mathrm{H}$ from 800 to $795 \mathrm{~cm}^{-1}$ could be ascribed to a decrease in the electron density of $\mathrm{N}$ resulting from the coordination of $\mathrm{N}$ and $\mathrm{Mn}$ atoms. The additional band at $583 \mathrm{~cm}^{-1}$ could be attributed to $\mathrm{Mn}-\mathrm{N}$ vibration because of axial coordination between Mn and $\mathrm{N}$ atoms [21,22].

\subsection{XPS results}

The Mn $2 p$ XPS spectra of the samples are shown in Fig. 4. A peak centered at $642.1 \mathrm{eV}$ was observed for $\mathrm{TF}_{20} \mathrm{PPMnCl}$, which was in accordance with the binding energy of Mn $2 p_{3 / 2}$ reported for Mn(III) porphyrins [23]. Meanwhile, a peak centered at $642.4 \mathrm{eV}$ was observed for 5-Mn(TF5 PP)-MCM-41. The slight shift $(0.3 \mathrm{eV})$ demonstrated the difference in the coordination environment of the $\mathrm{Mn}$ atoms, which seemed to indicate axial coordination of manganese porphyrins with $-\mathrm{NH}_{2}$ grafted on the mesoporous MCM-41.

\subsection{SEM results}

Fig. 5 shows SEM images for MCM-41 and 5-Mn(TF 5 PP)MCM-41. Compared with MCM-41, 5-Mn(TF5 PP)-MCM-41 had an irregular surface, possibly because of the formation of organic species on the surface of the catalyst. This observation may support the FT-IR results.

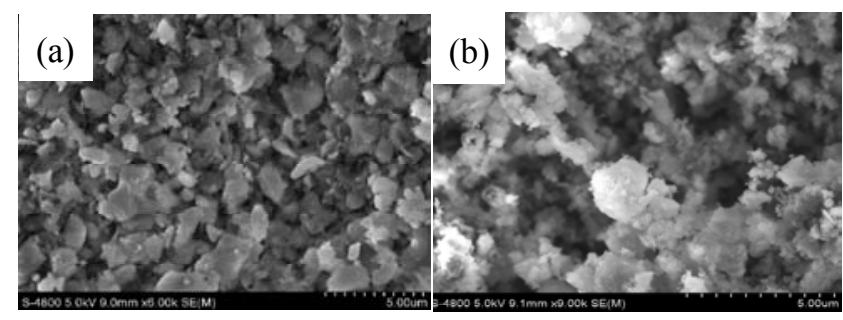

Fig. 5. SEM images of MCM-41 (a) and 5-Mn(TFF $P P)-M C M-41(b)$. 


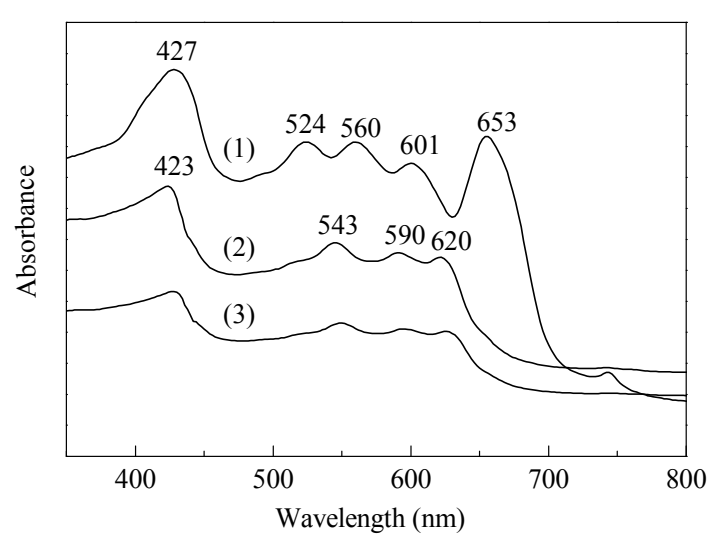

Fig. 6. Diffuse reflectance UV-Vis spectra of $\mathrm{H}_{2} \mathrm{TF}_{20} \mathrm{PP}(1), \mathrm{TF}_{20} \mathrm{PPMnCl}$ (2), and 5-Mn( $\left.\mathrm{TF}_{5} \mathrm{PP}\right)-\mathrm{MCM}-41$ (3).

\subsection{UV-Vis results}

Diffuse reflectance UV-Vis spectra of $\mathrm{H}_{2} \mathrm{TF}_{20} \mathrm{PP}, \mathrm{TF}_{20} \mathrm{PPMnCl}$ and 5-Mn(TF5 $\mathrm{PP})-\mathrm{MCM}-41$ are shown in Fig. 6. The UV-Vis absorption bands of porphyrins are attributed to electronic transitions from the ground state $\left(\mathrm{S}_{0}\right)$ to the two lowest singlet excited states, $S_{1}$ (Q state) and $S_{2}$ (Soret state) [24]. The $S_{0} \rightarrow S_{1}$ transition exhibits weak $\mathrm{Q}$ bands in the visible light region, while the $\mathrm{S}_{0} \rightarrow \mathrm{S}_{2}$ transition produces a strong Soret band in the near UV region [25,26]. In Fig. 5, $\mathrm{H}_{2} \mathrm{TF}_{20} \mathrm{CPP}$ showed a Soret band at $427 \mathrm{~nm}$ and four $Q$ bands at 524, 560, 601, and $653 \mathrm{~nm}$, which correspond to four characteristic absorptions of the transitions $\mathrm{Qx}(0,0), \mathrm{Qx}(0,1), \mathrm{Qy}(0,0)$, and $\mathrm{Qy}(0,1)$, respectively. For $\mathrm{TF}_{20} \mathrm{PPMnCl}$, when $\mathrm{Mn}$ ions were anchored to the tetrapyrrole ring of the porphyrins, the symmetry of the molecule was changed from $\mathrm{D}_{2 \mathrm{~h}}$ to $\mathrm{D}_{4 \mathrm{~h}}$ [27]. Accordingly, the absorption spectra were also altered to some extent. Moreover, because of coordination between Mn and porphyrins, the fourth $Q$ band ( $653 \mathrm{~nm}$ ) disappeared while the other three $\mathrm{Q}$ bands became weaker and red shifted.

The spectrum of $5-\mathrm{Mn}\left(\mathrm{TF}_{5} \mathrm{PP}\right)-\mathrm{MCM}-41$ was similar to that of $\mathrm{TF}_{20} \mathrm{PPMnCl}$, indicating that the structure of the manganese porphyrin did not alter after incorporation into the composite system.

\subsection{TG-DSC results}

TG-DSC was conducted quantitatively to evaluate the content of the modifiers (Fig. 7). Several maxima were observed in the obtained DSC curve. The first change in the curve between 50 to $100{ }^{\circ} \mathrm{C}$ was assigned to removal of physically adsorbed water on the surface; this corresponded to an approximately $10 \%$ mass loss. Additional mass losses centered at 300, 425, and $542{ }^{\circ} \mathrm{C}$ were observed, which were attributed to elimination of surface bound organic groups. The results also indicated that the $\mathrm{Mn}\left(\mathrm{TF}_{5} \mathrm{PP}\right)-\mathrm{MCM}-41$ catalysts were thermally stable up to $300{ }^{\circ} \mathrm{C}$.

\subsection{Catalytic tests}

The catalytic activity of $\mathrm{Mn}\left(\mathrm{TF}_{5} \mathrm{PP}\right)-\mathrm{MCM}-41$ catalysts with

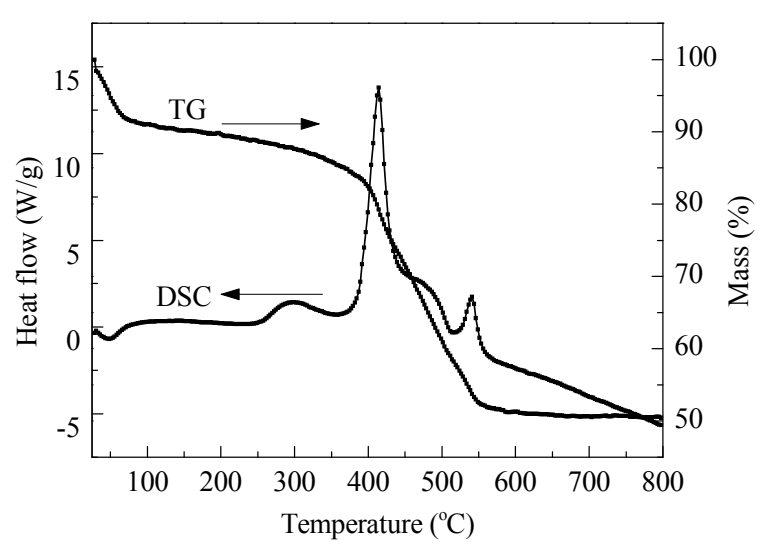

Fig. 7. TG-DSC curves of 5-Mn( $\left.\mathrm{TF}_{5} \mathrm{PP}\right)-\mathrm{MCM}-41$.

different Mn contents was evaluated in the hydroxylation of naphthalene using $m$-CPBA as the oxidant. The results in Table 2 demonstrated that increasing the loading of manganese porphyrin led to an increase in the catalytic activity of the material. The best overall result was obtained with 5-Mn( $\left.\mathrm{TF}_{5} \mathrm{PP}\right)$ MCM-41, which gave a maximum yield of $22.5 \%$ for 1-naphthol. Compared with other heterogeneous catalysts from earlier studies, the heterogeneous manganese porphyrins catalysts from the present study showed relatively high catalytic activity. This may be attributed to the unique catalytic process of the $\mathrm{Mn}\left(\mathrm{TF}_{5} \mathrm{PP}\right)-\mathrm{MCM}-41$ catalyst. In aprotic solutions, manganese porphyrins are oxidized to manganese peroxy complexes (TF5P)MnOOAr, which react with substituted sites on the naphthalene ring. During this reaction, manganese porphyrins play a role in transferring oxygen. The presence of fluorine substituents may lead to higher stability of manganese porphyrins and reduce over-oxidation. Meanwhile, fluorine substituents can reinforce the redox potential of manganese porphyrins and improve the catalytic activity [28].

Compared with homogeneous manganese porphyrin catalysts, $\mathrm{Mn}\left(\mathrm{TF}_{5} \mathrm{PP}\right)-\mathrm{MCM}-41$ showed relatively low catalytic activity. This could be explained by the axial coordination between $\mathrm{Mn}$ ions and $\mathrm{NH}_{2}-$ reducing the possibility of collisions between reactants and active metal ions [29]. However, the heterogeneous manganese porphyrin catalyst exhibited good reusability. As shown in recycling tests (Table 3), Mn( $\left.\mathrm{TF}_{5} \mathrm{PP}\right)$ MCM-41 showed high conversion and selectivity without ob-

\section{Table 2}

Catalytic activity of $\left.\mathrm{Mn} \mathrm{TF}_{5} \mathrm{PP}\right)-\mathrm{MCM}-41$ for hydroxylation of naphthalene.

\begin{tabular}{|c|c|c|c|c|}
\hline Catalyst & $\begin{array}{c}\mathrm{Mn} / \mathrm{Si} \\
\text { molar ratio }\end{array}$ & $\begin{array}{c}\text { Conversion } \\
(\%)\end{array}$ & $\begin{array}{r}\text { Selectiv } \\
\text { 1-Naphthol }\end{array}$ & $\frac{\text { ity (\%) }}{2 \text {-Naphthol }}$ \\
\hline 2-Mn(TF 5 PP)-MCM-41 & 0.0046 & 19.4 & 70 & 3 \\
\hline 3-Mn(TF TF $\left._{5} \mathrm{PP}\right)-\mathrm{MCM}-41$ & 0.0084 & 24.3 & 71 & 4 \\
\hline 4-Mn(TF5 $\mathrm{PP})-\mathrm{MCM}-41$ & 0.0092 & 30.6 & 70 & 5 \\
\hline 5-Mn(TFF $\mathrm{PP})-\mathrm{MCM}-41$ & 0.0093 & 31.2 & 72 & 3 \\
\hline $\mathrm{TF}_{20} \mathrm{CPPMnCl}[8]$ & - & 54.5 & 93 & trace \\
\hline Fe-MCM-41 [12] & - & 5.1 & 6.5 & 3.5 \\
\hline V-MCM-41 [13] & - & 10 & - & - \\
\hline
\end{tabular}

Reaction conditions: Substrate $/ m$-CPBA $=1 / 1.2$ (molar ratio), $30{ }^{\circ} \mathrm{C}, 4$ h, $1 \mathrm{~g}$ of substrate and $0.1 \mathrm{~g}$ of catalyst in $40 \mathrm{~mL}$ of $\mathrm{CH}_{3} \mathrm{CN} / \mathrm{CH}_{2} \mathrm{Cl}_{2}$ (1:1, $V / V$ ) mixed solvent. 
Table 3

Reusability of Mn(TF5 $\mathrm{PP})-\mathrm{MCM}-41$ for naphthalene hydroxylation ${ }^{\mathrm{a}}$

\begin{tabular}{lccc}
\hline \multirow{2}{*}{ Run } & \multirow{2}{*}{ Conversion (\%) } & \multicolumn{2}{c}{ Selectivity (\%) } \\
\cline { 2 - 4 } & 31.2 & 72 & 1-Naphthol \\
2 & 29.3 & 71 & 3 \\
2 & 27.8 & 68 & 5 \\
3 & 27.6 & 68 & 4 \\
4 & 27.3 & 70 & 4 \\
5 &
\end{tabular}

Reaction conditions: Substrate $/ m$-CPBA $=1 / 1.2$ (molar ratio), $30^{\circ} \mathrm{C}, 4$ h, $1 \mathrm{~g}$ of substrate and $0.1 \mathrm{~g}$ of catalyst in $40 \mathrm{~mL}$ of $\mathrm{CH}_{3} \mathrm{CN} / \mathrm{CH}_{2} \mathrm{Cl}_{2}$ (volume ratio $=1 / 1$ ) mixed solvent, sample $5-\mathrm{Mn}\left(\mathrm{TF}_{5} \mathrm{PP}\right)-\mathrm{MCM}-41$ was reused in naphthalene hydroxylation.

servable leaching of the complex ( $\mathrm{Mn} / \mathrm{Si}$ mole ratio after five runs was 0.0072 ). The obtained catalytic results highlight the potential of the synthesized $\mathrm{Mn}\left(\mathrm{TF}_{5} \mathrm{PP}\right)-\mathrm{MCM}-41$ as a catalyst for the catalytic oxidation of naphthalene in a heterogeneous system.

\section{Conclusions}

A catalyst was constructed by immobilizing manganese porphyrins on amino-functionalized MCM-41. The catalytic activity of this material could be changed by altering the amounts of metalloporphyrin immobilized on the MCM-41. Compared with existing homogeneous manganese porphyrins systems, the produced catalyst showed better stability and comparable catalytic activity. It gave much higher naphthalene conversion than other heterogeneous catalysts. The catalyst could be reused more than five times without obvious loss in its activity and selectivity.

\section{References}

[1] Zhang G Y, Long J L, Wang X X, Zhang Z Z, Dai W X, Liu P, Li Z H, Wu L, Fu X Z. Langmuir, 2010, 26: 1362

[2] Shi H X, Zhang T Y, Wang H L, Wang X, He M. Chin J Catal (史慧贤,
张天永, 王红亮, 王晓, 何萌. 催化学报), 2011, 32: 46

[3] Xu D, Jia L H, Guo X F. Chin J Catal (徐丹, 贾丽华, 郭祥峰. 催化学 报), 2013, 34: 341

[4] Chen D D, Li N K, Sun P, Kong Y. Chin J Catal (陈丹丹, 李年凯, 孙 鹏, 孔岩. 催化学报), 2009, 30:643

[5] Jiang S Y, Kong Y, Wu C, Xu Z, Zhu H Y, Wang C Y, Wang J, Yan Q J. Chin J Catal (蒋斯扬, 孔岩, 吴丞, 徐铮, 朱海洋, 王春燕, 王军, 颜 其洁. 催化学报), 2006, 27: 421

[6] Kong Y, Xu X J, Wu Y, Zhang R, Wang J. Chin J Catal (孔岩, 徐金金, 吴勇, 张瑞, 王军. 催化学报), 2008, 29: 385

[7] Maurya M R, Kumar A, Costa Pessoa J. Coord Chem Rev, 2011, 255: 2315

[8] Chen C D, Sheng W B, Shi G J, Guo C C. J Phys Org Chem, 2013, 26: 23

[9] Carrier M N, Scheer C, Gouvine P, Bartoli J F, Battioni P, Mansuy D. Tetrahedron Lett, 1990, 31: 6645

[10] Bartoli J F, Mouries-Mansuy V, Le Barch-Ozette K, Palacio M, Battioni P, Mansuy D. Chem Commun, 2000: 827

[11] Khavasi H R, Davarani S S H, Safari N.J Mol Catal A, 2002, 188: 115

[12] Bango A, Halasz J. React Kinet Catal Lett, 2009, 96: 413

[13] Shylesh S, Singh A P. J Catal, 2004, 228: 333

[14] Beck J S, Vartuli J C, Roth W J, Leonowicz M E, Kresge C T, Schmitt K D, Chu C T W, Olson D H, Sheppard E W, McCullen S B, Higgins J B, Schlenker J L. J Am Chem Soc, 1992, 114: 10834

[15] Pereira C, Biernacki K, Rebelo S L H, Magalhães A L, Carvalho A P, Pires J, Freire C. J Mol Catal A, 2009, 312: 53

[16] Lindsey J S, Hsu H C, Schreiman I C. Tetrahedron Lett, 1986, 27 : 4969

[17] Zhu Q Q, Maeno S, Nishimoto R, Miyamoto T, Fukushima M. J Mol Catal A, 2014, 385: 31

[18] Gaspar H, Andrade M, Pereira C, Pereira A M, Rebelo S L H, Araújo J P, Pires J, Carvalho A P, Freire C. Catal Today, 2013, 203: 103

[19] Yang X Y, Han Y, Lin K F, Tian G, Feng Y F, Meng X J, Di Y, Du Y C, Zhang Y L, Xiao F S. Chem Commun, 2004: 2612

[20] Hao S Y, Chang H, Xiao Q, Zhong Y J, Zhu W P. J Phys Chem C, 2011, 115: 12873

[21] Kalbasi R J, Massah A R, Zamani F, Bain A D, Berno B. J Porous Mater, 2011, 18: 475

[22] Hu G H, Ruan W J, Zhang Y L, Han H, Zhu Z A. Acta Phys-Chim Sin (胡国航，阮文娟，张玉玲，韩华，朱志昂. 物理化学学报), 2003, 19: 320

\section{Graphical Abstract}

Chin. J. Catal., 2015, 36: 1035-1041 doi: 10.1016/S1872-2067(15)60836-1

Coordination of manganese porphyrins on amino-functionalized MCM-41 for heterogeneous catalysis of naphthalene hydroxylation

Fu Yang, Shuying Gao, Cuirong Xiong, Haiqing Wang, Jin Chen, Yan Kong*

Nanjing Tech University

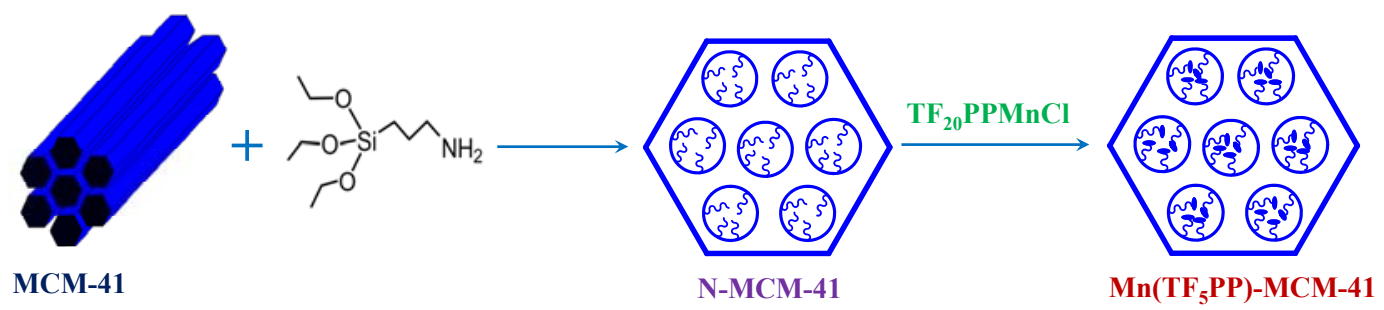

Polyhalogenated manganese porphyrins with fluorine substituents were anchored on amino-functionalized MCM-41 to produce a heterogeneous catalyst, which exhibited remarkable catalytic activity and desirable reusability in the hydroxylation of naphthalene. 
[23] Kaplan A, Korin E, Bettelheim A. Eur J Inorg Chem, 2014, 2014: 2288

[24] Guo X M, Shi T S. J Mol Struct, 2006, 789: 8

[25] Qi M H, Liu G F. Solid State Sci, 2004, 6: 287

[26] Chen D M, Zhang Y H, He T J, Liu F C. Spectrochim Acta A, 2002, 58:
2291

[27] Wang B B, Zhang L M, Li B, Li Y, Shi Y H, Shi T S. Sens Actuators B, 2014, 190: 93

[28] Fujii H. J Am Chem Soc, 1993, 115: 4641

[29] Poltowicz J, Haber J.J Mol Catal A, 2004, 220: 43

\title{
氨功能化介孔MCM-41固载锰卟啉作为萗羟基化多相催化剂
}

杨 福, 高树英, 熊翠蓉, 王海青, 陈 进, 孔 岩*

\author{
南京工业大学化学化工学院材料化学工程国家重点实验室, 江苏南京210009
}

摘要: 将不同含量的四(五氟苯基)卟啉锰固载于表面氨基功能化的MCM-41介孔分子篮,所得样品通过粉末X射线衍射、氮气吸附 脱附、傅里叶变换红外光谱、X射线光电子能谱、扫描电子显微镜、漫反射紫外-可见光谱、热重和差示扫描量热、电感耦合等 离子体进行了表征. 结果表明, 四(五氟苯基)卟啉锰通过Mn与氨基的轴向配位固载于MCM-41. 所制备的样品作为多相催化剂在 以间氯过氧苯甲酸为氧化剂选择氧化芸反应中表现出良好的催化性能, 且多次使用后没有明显的活性损失.

关键词：锰卟啉; 固载; 轴向配位; 萗羟基化; 多相催化

收稿日期: 2015-01-09. 接受日期: 2015-03-17. 出版日期: 2015-07-20.

*通讯联系人. 电话/传真: (025)83587860; 电子信箱: kongy36@njtech.edu.cn

基金来源：国家自然科学基金(21276125, 21476108).

本文的英文电子版由Elsevier出版社在ScienceDirect上出版(http://www.sciencedirect.com/science/journal/18722067). 